\title{
Analisis Faktor-Faktor yang Mempengaruhi Jumlah Penduduk di Kota Semarang Menggunakan Metode Regresi Data Panel
}

\author{
Prizka Rismawati Arum ${ }^{(1)}$, M. Al Haris ${ }^{(2)}$ \\ Universitas Muhammadiyah Semarang \\ Jalan Kedungmundu Raya No.22 Tembalang, Kota Semarang 50273 \\ e-mail: prizka.rismawatiarum@unimus.ac.id
}

\begin{abstract}
ABSTRAK
Penduduk adalah semua orang yang berdomisili di wilayah geografis Indonesia selama enam bulan atau lebih dan atau mereka yang berdomisili kurang dari enam bulan tetapi bertujuan menetap. Pertumbuhan penduduk diakibatkan oleh dua komponen yaitu: fertilitas dan mortalitas. Untuk mengetahui seberapa besar keterkaitan antara jumlah penduduk dengan jumlah kelahiran dan kematian di setiap kecamataan Kota Semarang, harus diamati dalam beberapa periode waktu tertentu dan beberapa tempat secara bersamaan. Sehingga dalam penelitian ini digunakan metode regresi data panel. Dalam pengujian regresi data panel, didapatkan hasil bahwa Model regresi data panel yang terbentuk untuk mengetahui faktor-faktor yang mempengaruhi tingkat jumlah penduduk adalah model random Effect. Pada model tersebut semua asumsi terpenuhi. Faktor yang signifikan mempengaruhi jumlah penduduk adalah jumlah kelahiran. Kelahiran dan kematian mempengaruhi jumlah penduduk sebesar $99.95 \%$ dan sisanya sebesar $0.05 \%$ dipengaruhi oleh faktor- faktor lain yang tidak di teliti.
\end{abstract}

Kata kunci : jumlah penduduk, regresi data panel, model random effect.

\begin{abstract}
Residents are all people who live in the geographical area of Indonesia for six months or more and or those who have been domiciled for less than six months but aim to settle. Population growth is caused by two components, namely: fertility and mortality. To find out how big the relationship between the population and the number of births and deaths in each sub-district of Semarang, must observed in several specific time periods and places at once. So in this study, the panel data regression method was used. In panel data regression testing, the results show that the panel data regression model formed to determine the factors that influence the level of population is the random effect model. In this model all assumptions are fulfilled. Significant factors affecting population are number of births. Births and deaths affect the population of $99.95 \%$ and the remaining $0.05 \%$ is influenced by other factors not examined.
\end{abstract}

Keywords : population density, panel regression, random effect model.

\section{PENDAHULUAN}

Penduduk adalah semua orang ang berdomisili di wilayah geografis Indonesia selama enam bulan atau lebih dan atau mereka yang berdomisili kurang dari enam bulan tetapi bertujuan menetap. Pertumbuhan penduduk diakibatkan oleh tiga komponen yaitu: fertilitas, mortalitas dan migrasi. Pertumbuhan penduduk adalah angka yang menunjukkan tinkat pertambahan penduduk pertahun dalam jangka waktu tertentu.

Kota Semarang merupakan ibu kota provinsi Jawa Tengah, yang merupakan wilayah dengan jumlah penduduk terbanyak ke 4 di Jawa Tengah dengan jumlah penduduk pada tahun 2018 sebesar
1.668.558 penduduk/jiwa. Kota Semarang dibagi menjadi 16 kecamatan. Faktor-faktor yang mempengaruhi banyaknya jumlah penduduk di Kota Semarang diantaranya Kelahiran dan Kematian.

Jumlah kelahiran di Kota Semarang pada tahun 2018 yaitu sebesar 15.659 penduduk/jiwa. Sedangkan jumlah kematian di Kota Semarang pada tahun 2018 Sebesar 8.788 penduduk/jiwa. Kedua faktor tersebut mengalami penurunan dari tahun sebelumnya. Untuk mengetahui seberapa besar keterkaitan antara jumlah penduduk dengan jumlah kelahiran dan kematian di kecamatan Kota Semarang harus juga mempertimbangkan perubahan dari waktu ke waktu yang tidak bisa diselesaikan dengan analisis 
statistika biasa. Maka dibutuhkan analisis yang dapat mengamati data dalam beberapa periode waktu tertentu dan tempat secara sekaligus. Sehingga dalam penelitian ini digunakan metode regresi data panel.

Regresi data panel menurut Widarjono (2009), data panel adalah gabungan antara data time series (runtun waktu) dan data crossection (individual). Pada data time series, satu atau lebih variabel akan diamati pada satu unit observasi dalam kurun waktu tertentu. Sedangkan data crossection merupakan amatan dari beberapa unit observasi dalam satu titik tertentu. Kelebihan Regresi data panel antara lain :

1. Memberikan peneliti jumlah pengamatan yang besar, meningkatkan degree of freedom, data memiliki variabilitas yang besar, dan mengurangi kolinieritas antara variabel penjelas sehingga menghasilkan estimasi ekonometri yang efisien.

2. Memberikan informasi lebih banyak yang tidak dapat diberikan oleh data time series ataupun data crossection.

3. Memberikan penyelesaian yang lebih baik dibandingkan data crossection.

\section{Regresi Data Panel}

Menurut Widarjono (2009), data panel adalah gabungan antara data time series (runtun waktu) dan data cross section (individual). Secara umum, model regresi data panel dapat dinyatakan sebagai berikut:

$y_{i t}=X_{i t} \beta+\mu_{i}+\mu_{i t}$

dengan:

i : indeks unit; $\mathrm{i}=1,2,3, \ldots, \mathrm{N}$

$\mathrm{t} \quad$ : indeks periode waktu; $\mathrm{t}=1,2,3, \ldots, \mathrm{T}$

$y_{i t}$ : observasi variabel dependen pada unit i dan waktu $\mathrm{t}$

$X_{i t}$ : variabel independen berupa vektor baris berukuran $1 \mathrm{x}$ k, dengan $\mathrm{k}$ adalah banyaknya variabel independen

$\beta \quad$ : vektor parameter berukuran $\mathrm{k} \times 1$

$\mu_{i t} \quad$ : error unit individu ke-i dan unit waktu ke-t

Estimasi Model Regresi Panel

Dalam melakukan estimasi model regresi dengan data panel terdapat tiga pendekatan yang sering digunakan, yaitu pendekatan model Common Effect, model Fixed Effect, dan model Random Effect.

1. Model Common Effect

Model Common Effect merupakan teknik yang paling sederhana untuk mengestimasi model regresi data panel. Pendekatan ini mengabaikan heterogenitas antar unit cross section maupun antar waktu. Diasumsikan bahwa perilaku data antar unit cross section sama dalam berbagai kurun waktu. Dalam mengestimasi model common effect dapat dilakukan dengan metode Ordinary Least Square (OLS). Model common effect dapat dinyatakan sebagai berikut (Widarjono, 2009):

$y_{i t}=\alpha+X_{i t} \beta+u_{i t}$

dimana

$$
\begin{aligned}
i & =1,2, \ldots, N \\
t & =1,2, \ldots, T
\end{aligned}
$$

\section{Model fixed effect}

Menurut Gujarati (2003), salah satu cara untuk memperhatikan heterogenitas unit cross section pada model regresi data panel adalah dengan mengijinkan nilai intersep yang berbeda-beda untuk setiap unit cross section tetapi masih mengasumsikan slope konstan. Model fixed effect dapat dinyatakan sebagai berikut:

$y_{i t}=\alpha_{i}+X_{i t} \beta+u_{i t}$

dimana

$$
\begin{aligned}
i & =1,2, \ldots, N \\
t & =1,2, \ldots, T
\end{aligned}
$$

Terdapat dua pendekatan untuk model fixed effect, yaitu model fixed effect within group (WG) dengan mengelimasi efek unit cross section dan model fixed effect least square dummy variabel (LSDV) dengan menggunakan variabel dummy.

3. Model Random Effect

Pendekatan Random Effect Model (REM) mengasumsikan setiap unit cross section mempunyai perbedaan intersep. Namun demikian, diasumsikan bahwa intersep $a_{i}$ adalah variabel acak dengan mean $a_{0}$. Sehingga intersep dapat ditulis sebagai $a_{i}=a_{0}+\varepsilon_{i}$ dengan $\varepsilon_{i}$ merupakan error random yang mempunyai mean nol dan varian $\sigma_{\mathrm{u}}^{2}$. Model random effect dapat dinyatakan sebagai berikut (Gujarati, 2003):

$y_{i t}=\alpha_{0}+X_{i t} \beta+w_{i t}$

dimana

$$
i=1,2, \ldots, n
$$$$
t=1,2, \ldots, T
$$

dengan, $w_{i t}=\varepsilon_{i}+u_{i t}, \varepsilon_{i}$ adalah error secara menyeluruh yang merupakan kombinasi time series dan cross section. Estimasi model 
random effect dilakukan dengan metode Generalized Least Square (GLS).

\section{Uji Spesifikasi Model}

a. Uji Chow

$\mathrm{H}_{0}$ diterima, maka model yang digunakan adalah common effect. $\mathrm{H}_{0}$ ditolak, maka model yang digunakan adalah fixed effect.

b. Uji Hausman

$\mathrm{H}_{0}$ diterima, maka model yang digunakan adalah random effect. $H_{0}$ ditolak, maka model yang digunakan adalah fixed effect.

c. Uji LM

$\mathrm{H}_{0}$ di terima, maka model yang digunakan adalah fixed effect. $\mathrm{H}_{0}$ di tolak, maka model yang digunakan adalah random effect.

\section{Uji Asumsi}

Uji asumsi untuk analisis regresi panel meliputi uji normalitas, uji multikolinearitas, uji heteroskedastisitas, dan uji autokorelasi.

a. Uji Normalitas

Uji normalias redisual digunakan untuk mendeteksi apakah residual berdistribusi normal atau tidak. Uji normalitas residual secara formal dapat dideteksi dari metode yang dikembangkan oleh Shapiro-Wilk.

b. Uji Multikolinearitas

Multikolinearitas berarti adanya hubungan linier antara variabel independen di dalam model regresi. Salah satu cara untuk mendeteksi adanya multikolinearitas adalah dengan menghitung nilai Variance Inflation Factor (VIF).

c. Uji Heteroskedastisitas

- Pengujian Asumsi Heteroskedastisitas Antar Unit Cross Section. Pengujian adanya heteroskedastisitas pada regresi panel dapat dilakukan dengan uji Lagrange Multiplier (LM).

- Pengujian Aumsi Autokorelasi Antar Unit Cross Section. Jika dari pengujian asumsi heteroskedastisitas, didapatkan kesimpulan terjadi heteroskedastisitas pada varianscovarians residual, selanjutnya dilakukan pengujian korelasi antarunit cross section.

d. Uji Autokorelasi

Autokorelasi merupakan korelasi antara satu komponen residual dengan komponen residual yang lain. Salah satu uji yang biasa digunakan adalah metode yang dikemukakan oleh DurbinWatson.

\section{Uji Signifikansi Parameter}

Uji signifikansi parameter meliputi uji Serentak dan uji Parsial. a. Uji Serentak

Uji serentak digunakan untuk mengetahui pengaruh semua variabel independen terhadap variabel dependen, dengan hipotesis berikut:

$$
\begin{aligned}
H_{0}: & \beta_{1}=\beta_{2}=\ldots=\beta_{k} \\
H_{l}: & \text { sekurang-kurangnya ada satu } \beta_{k} \neq 0, \\
& \text { dengan } j=1,2
\end{aligned}
$$

b. Uji Parsial

Uji parsial digunakan untuk mengetahui variabel independen yang berpengaruh signifikan seara individu terhadap variabel dependen, dengan hipotesis sebagai berikut:

$$
\begin{aligned}
& H_{0}: \quad \beta_{j}=0 \\
& H_{l}: \quad \beta_{j} \neq 0, \text { dengan } j=1,2, . ., k
\end{aligned}
$$

\section{METODE PENELITIAN}

Data yang digunakan dalam penelitian ini adalah data sekunder yang terdiri dari data jumlah penduduk, kelahiran, dan kematian pada setiap kecamatan di Kota Semarang yang bersumber dari Dinas Kependudukan dan Pencatatan Sipil Kota Semarang. Data tersebut berbentuk tahunan dari tahun 2014 sampai dengan tahun 2018. Variabel dependen dalam penelitian ini adalah Jumlah Penduduk (Y) dengan variabel independen adalah jumlah kelahiran $\left(\mathrm{X}_{1}\right)$ dan jumlah kematian $\left(\mathrm{X}_{2}\right)$.

Metode penelitian yang digunakan yaitu regresi data panel. Penelitian ini bertujuan untuk mengetahui seberapa besar pengaruh dari jumlah kelahiran dan jumlah kematian terhadap jumlah penduduk pada setiap kecamatan di Kota Semarang. Adapun langkah-langkah dalam penelitian yang dilakukan adalah sebagai berikut :

1. Melakukan analisis desktiptif

2. Melakukan uji spesifikasi model.

3. Melakukan uji asumsi pada model yang terpilih.

4. Mekakukan uji signifikansi parameter yang meliputi uji serentak dan uji parsial.

5. Melakukan interpretasi model regresi data panel. Menarik kesimpulan.

\section{HASIL DAN PEMBAHASAN}

\subsection{Analisis Deskriptif}

Berdasarkan Gambar 1 diketahui bahwa scatter plot yang terbentuk mengikuti garis linier meskipun ada beberapa data yang diduga outlier. Hal ini dapat menunjukkan bahwa terdapat hubungan linier antara Jumlah Penduduk dengan Kelahiran. 


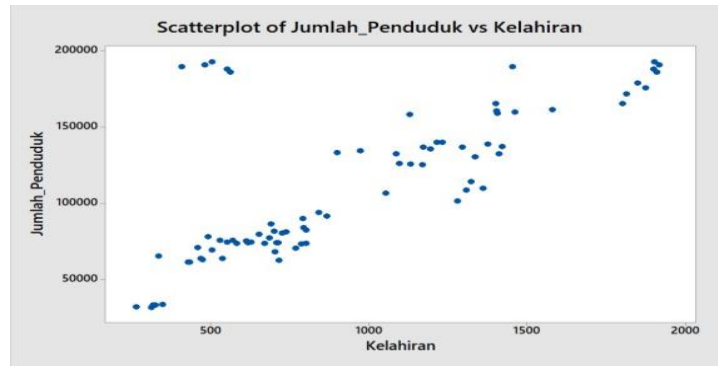

Gambar 1. Scatter Plot Jumlah Penduduk dan Kelahiran.

Berdasarkan Gambar 2 diketahui bahwa scatter plot yang terbentuk mengikuti garis linier. Hal ini dapat menunjukkan bahwa juga terdapat hubungan antara Jumlah Penduduk dengan Kematian.

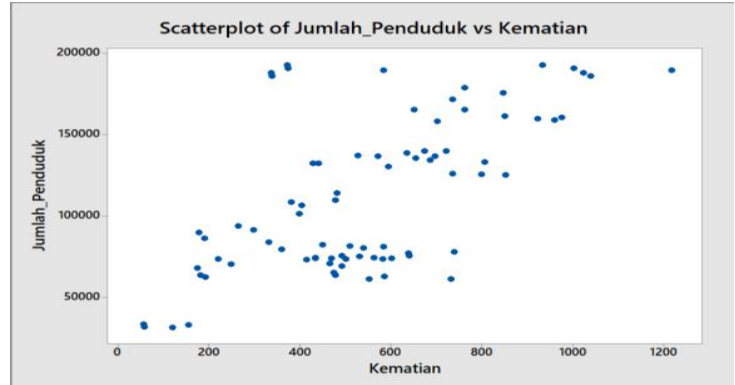

Gambar 2. Scatter Plot Jumlah Penduduk dan Kematian.

\subsection{Uji Spesifikasi Model}

1) Uji Chow

$\begin{array}{ll}\text { Hipotesis: } & H_{0}: \text { model common effect } \\ & H_{1}: \text { model fixed effect }\end{array}$

Tabel 1. Uji Chow

\begin{tabular}{|l|l|}
\hline \multicolumn{2}{|c|}{ Chow Test } \\
\hline F & 571.85 \\
\hline$p$-value & $2.2 \mathrm{e}-16$ \\
\hline
\end{tabular}

Berdasarkan Tabel 1 diketahui bahwa nilai $p$-value $(2.2 \mathrm{e}-16)<\alpha(0.05)$ maka $H_{0}$ ditolak, artinya model yang digunakan adalah fixed effect.

2) Uji Hausman

Hipotesis: $\quad H_{0}:$ model random effect

Tabel 2. Uji Hausman

$$
H_{1} \text { : model fixed effect }
$$

\begin{tabular}{|l|l|}
\hline \multicolumn{2}{|c|}{ Hausman Test } \\
\hline Chisq & 5.5985 \\
\hline$p$-value & 0.06085 \\
\hline
\end{tabular}

Berdasarkan Tabel 2 diketahui bahwa nilai $p$-value $(0.06085)>\alpha(0.05)$ maka $H_{0}$ diterima, artinya model yang digunakan adalah random effect.
3) Uji Lagrange Multiplier

$$
\text { Hipotesis: } \quad H_{0} \text { : model common effect }
$$$$
H_{1} \text { : model random effect }
$$

Tabel 3. Uji Lagrange Multiplier

\begin{tabular}{|l|l|}
\hline \multicolumn{2}{|c|}{ Hausman Test } \\
\hline Normal & 11.995 \\
\hline$p$-value & $2.2 \mathrm{e}-16$ \\
\hline
\end{tabular}

Berdasarkan Tabel 3 diketahui bahwa nilai $p$-value $(2.2 \mathrm{e}-16)<\alpha(0.05)$ maka $H_{0}$ ditolak, artinya berdasarkan hasil uji spesifikasi model dapat disimpulkan bahwa variabel jumlah penduduk dan faktorfaktor yang mempengaruhinya menggunakan model regresi data panel random effect.

\subsection{Uji Asumsi}

1) Uji Normalitas Hipotesis:

$H_{0}$ : Residual berdistribusi normal

$H_{l}$ : Residual tidak berdistribusi normal

Tabel 4. Uji Normalitas

\begin{tabular}{|l|l|}
\hline \multicolumn{2}{|c|}{ Shapiro - Wilk Test } \\
\hline $\mathrm{W}$ & 0.98243 \\
\hline$p$-value & 0.3407 \\
\hline
\end{tabular}

Berdasarkan Tabel 4 diketahui bahwa nilai $p$-value $(0.3407) \geq \alpha(0.05)$ maka $H_{0}$ diterima, artinya residual berdistribusi normal.

2) Uji Multikolinearitas

Tabel 5. Uji Multikolinearitas

\begin{tabular}{|l|l|}
\hline \multicolumn{2}{|c|}{ VIF } \\
\hline Kelahiran & 1.830109 \\
\hline Kematian & 1.830109 \\
\hline
\end{tabular}

Berdasarkan Tabel 5 diketahui bahwa masingmasing variabel memiliki nilai VIF $<10$, maka secara signifikan dapat disimpulkan bahwa tidak terdapat multikolinearitas.

3) Uji Heteroskedastisitas

Hipotesis:

$H_{0}$ : Tidak terjadi heteroskedastisitas

$H_{l}$ : Terjadi heteroskedastisitas

Tabel 6. Uji Heteroskedastisitas

\begin{tabular}{|l|l|}
\hline \multicolumn{2}{|l|}{ Pesaran CD test } \\
\hline$Z$ & -1.3205 \\
\hline$p$-value & 0.1867 \\
\hline
\end{tabular}


Berdasarkan Tabel 6 diketahui bahwa nilai $p$ value $(0.1867) \geq \alpha(0.05)$ maka $H_{0}$ diterima, artinya tidak terjadi heteroskedastisitas.

4) Uji Autokorelasi

Hipotesis:

$H_{0} \quad: \rho=0$ (tidak ada autokorelasi)

$H_{l} \quad: \rho \neq 0$ (ada autokorelasi)

Tabel 7. Uji Autokorelasi

\begin{tabular}{|l|l|}
\hline \multicolumn{2}{|l|}{ Durbin-Watson Test } \\
\hline DW & 1.9749 \\
\hline$p$-value & 0.462 \\
\hline
\end{tabular}

Berdasarkan Tabel 7 diketahui bahwa nilai $p$-value $(0.462) \geq \alpha(0.05)$ maka $H_{0}$ diterima, artinya tidak ada autokorelasi.

\subsection{Uji Signifikansi Parameter}

1) Uji Serentak (Uji F)

Hipotesis:

$$
\begin{aligned}
H_{0}: & \beta_{1}=\beta_{2}=\ldots=\beta_{k} \\
H_{1}: & \text { sekurang-kurangnya ada satu } \beta_{k} \neq 0, \text { dengan } \\
& j=1,2
\end{aligned}
$$

Tabel 8. Uji Serentak

\begin{tabular}{|l|l|}
\hline $\mathrm{F}$ & 7246 \\
\hline$p$-value & $2.2 \mathrm{e}-16$ \\
\hline
\end{tabular}

Berdasarkan Tabel 8 telah diketahui $p$-value (2.2e16) $<\alpha(0,05)$ sehingga $\mathrm{H}_{0}$ ditolak. Jadi, dapat disimpulkan bahwa pada taraf signifikan 5\%, variabel kelahiran dan kematian berpengaruh signifikan terhadap jumlah penduduk.

2) Uji Parsial

a. Variabel Kelahiran

Hipotesis: $H_{0}: \beta_{1}=0$

$$
H_{1}: \beta_{1} \neq 0
$$

Tabel 9. Uji Parsial Kelahiran

\begin{tabular}{|l|l|}
\hline$Z$ & 3.3012 \\
\hline$p$-value & 0.0009627 \\
\hline
\end{tabular}

Berdasarkan Tabel 9 diketahui bahwa nilai $p$-value $(0.0009627)<\alpha(0.05)$ maka $H_{0}$ ditolak, artinya kelahiran mempengaruhi jumlah penduduk secara signifikan.

b. Variabel Kematian

$$
\text { Hipotesis: } \begin{aligned}
& H_{0}: \beta_{2}=0 \\
& H_{1}: \beta_{2} \neq 0
\end{aligned}
$$

Tabel 10. Uji Parsial Kematian

\begin{tabular}{|l|l|}
\hline$Z$ & 1.3623 \\
\hline$p$-value & 0.1731002 \\
\hline
\end{tabular}

Berdasarkan Tabel 10 Diketahui bahwa nilai $p$ value $(0.1731002)>\alpha(0.05)$ maka $H_{0}$ diterima, artinya kematian tidak mempengaruhi jumlah penduduk secara signifikan.

\subsection{Model Akhir Regresi Data Panel}

Berdasarkan pengujian yang telah dilakukan diperoleh model akhir regresi data panel untuk jumlah penduduk di Kota Semarang yaitu model Random Effect adalah sebagai berikut:

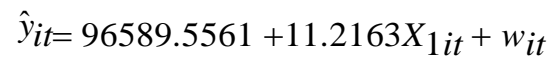

dengan,

$\hat{y}_{i t}$ : penduga jumlah penduduk ke- $i$ tahun ke- $t$

$X_{1 \text { it }}$ : jumlah kelahiran ke- $i$ tahun ke- $t$

$w_{i t}$ : error secara menyeluruh yang merupakan kombinasi time series dan cross section

Intepretasi dari model diatas adalah jika diasumsikan variabel lainnya dianggap tetap, maka jika kelahiran naik 1 satuan, akan meningkatkan jumlah penduduk sebesar 11.2163 satuan. Berdasarkan model diatas, diketahui koefisien determinasi $\left(R^{2}\right)$ sebesar $99.95 \%$ artinya persentase jumlah kelahiran dan tingkat kematian mempengaruhi jumlah penduduk sebesar $99.95 \%$ dan sisanya 0.05 dipengaruhi oleh faktor-faktor lain yang tidak di teliti.

\section{KESIMPULAN DAN SARAN}

Model regresi data panel yang terbentuk untuk mengetahui faktor- faktor yang mempengaruhi tingkat jumlah penduduk adalah model random Effect. Persamaan model tersebut adalah:

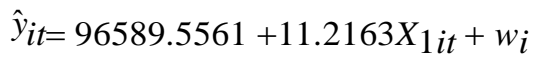

Pada model tersebut semua asumsi terpenuhi. Faktor yang signifikan mempengaruhi jumlah penduduk adalah jumlah kelahiran. Jika diasumsikan variabel lainnya dianggap tetap maka jika kelahiran naik 1 satuan akan meningkatkan jumlah penduduk sebesar 11.2163 satuan. Kelahiran dan kematian mempengaruhi jumlah penduduk sebesar $99.95 \%$ dan sisanya sebesar $0.05 \%$ dipengaruhi oleh faktorfaktor lain yang tidak di teliti. 
J Statistika Vol. 12, No. 2, (2019), Hal. 36-41

\section{DAFTAR PUSTAKA}

Asyiah N. 2018. Analisis Regresi Data Panel Dengan Pendekatan Common Effect Model (CEM), Fixed Effect Model (FEM), dan Random Effect Model (REM). Universitas Islam Indonesia.

Baltagi B. H. 2005. Econometrics Analysis of Panel Data. Ed ke-3. England (UK): John Wiley \& Sons Ltd.

BPS Provinsi Jawa Tengah. https://jateng.bps.go.id

Dinas Kependudukan dan Pencatatan Sipil Kota Semarang.

Ekananda, M. 2014. Analisis Ekonometrika Data Panel. Jakarta: Mitra Wacana Media.

Gujarati, D. 2003. Basic Econometrics Fourth Edition. New York: McGraw-Hill.

Gujarati, D. 2012. Dasar-Dasar Ekonometrika Edisi Lima. (diterjemahkan oleh: Mangunsong, R.C.). Jakarta: Salemba Empat.

Greene, W. H. 2003. Econometric Analisis (5 ed.). New jersey: Prentice-Hall Inc.

Hsiao, C. 2003. Analysis of Panel Data (2 ed.). New York: Cambridge University Press.

Hapsoro, D. N. Y. dan Gunanto. 2013. Analisis Pengaruh Variabel Makroekonomi Regional Terhadap Tingkat Kemiskinan di Perkotaan (Studi Kasus 44 kota di Indonesia 2007 2010). Diponegoro Journal of Economics. (2)1-12.

Melliana, A. dan Zain, I. 2013. Analisis Statistika Faktor yang Mempengaruhi Indeks Pembangunan Manusia di Kabupaten/Kota Provinsi Jawa Timur dengan Menggunakan Regresi Panel. Institut Teknologi Nopember.

Pangestika, S. 4111411057. 2015. Analisis Estimasi Model Regresi Data Panel Dengan Pendekatan Common Effect Model (CEM), Fixed Effect Model (FEM), Dan Random Effect Model $(R E M)$. Universitas Negeri Semarang. 